Published in final edited form as:

Clin Child Fam Psychol Rev. 2013 September ; 16(3): . doi:10.1007/s10567-013-0147-x.

\title{
Military Service, War, and Families: Considerations for Child Development, Prevention and Intervention, and Public Health Policy
}

Patricia Lester, MD, Blair Paley, PhD, and William Saltzman, PhD

With over a decade at war, the longest in United States history, the implications of wartime service for military connected children and families have emerged as a priority not only for the military community, but also for our national community. The wars in Iraq and Afghanistan have ushered in a new era of challenges for service members and their families. For an all-volunteer force engaged in prolonged wartime operations, multiple deployments may cumulatively span years across a child and family's development (Maholmes, 2012). Research on returning service members demonstrate an increased risk (estimated to be up to $30 \%$ ) for combat-related psychological health problems and traumatic brain injuries (Adamson et al. 2011, Tanelian et al, 2013), and the risk for suicide within the veteran population continues to rise, with recent reports documenting 22 suicide related deaths reported each day (Kemp and Bossarte, 2012). Furthermore, advances in injury care have improved survival rates for severe physical injuries, with long-term implications for service members, veterans and their caregiving families (Tanelian et al, 2013). Just as for service members serving in wartime operations, families too may experience the hardships of deployment and reintegration transitions in the context of dangerous duties. These challenges may be compounded by the impact of psychological and physical injury, and, for some, the profound impact of a loved one's death. And while the last decade has raised public awareness and accelerated research regarding the needs of military-connected children and families, there is still much we do not know about the specific and long-term impact of modern military service and how to preventively and strategically intervene to mitigate risk and promote resilience. Furthermore, developing a systemic and integrated public health approach that provides access to a continuum of high quality care for military and veteran families over time remains an unmet challenge.

Over the last several years, the field of research on military connected children and families has benefitted benefited tremendously from targeted research support undertaken by military commands and governmental agencies within the Department of Defense, and by national agencies and private organizations outside of it, often representing collaborative, interagency initiatives reflecting the broad reach and impact of these issues. Funding priorities for research and service needs for military connected families and children have been initiated through National Institute for Child and Human Development, as well as the National Institute for Drug and Alcohol (in collaboration with National Institute on Alcohol Abuse and Alcoholism and National Center for Complementary and Alternative Medicine), and Substance Abuse and Mental Health Services Administration. Furthermore, a range of private foundations (for example, the McCormick Foundation, Major League Baseball Foundation, California Community Foundation's Iraq Afghanistan Deployment Impact Fund ) and non-profit organizations (for example,. National Military Family Association, Military Child Education Coalition) have specifically supported military family and child research initiatives. These efforts have played a major role in launching a rapidly evolving knowledge base for guiding research, prevention and care for military children and families. 
Consistent with these efforts to advance a rigorous, interdisciplinary approach to this scientific and clinical dialogue, Clinical Child and Family Psychology Review has dedicated a two volume special issue (Volume 16, Issues 3 and 4, 2013) to developmental perspectives, family-centered prevention and intervention approaches, and public health considerations for military and veteran families affected by wartime service. Volume 1 of this special issue reviews emerging research in the context of developmental, family systems and social ecological frameworks, and explores the implications of these frameworks for integrating empirically supported prevention and intervention approaches that address the specific needs of military connected children and families. In Issue 4 of the special issue, our contributors explore the implications of these findings for service implementation, public policy and systems of care. This second volume will focus on an appraisal of current implementation issues, as well as institutional and community capacities to meet the longterm needs of military-connected children and families.

While written from multiple perspectives reflecting the inherently interdisciplinary nature of this field, these contributions converge around several overarching themes: 1) The experience of military service and post-military life is not an individual one, but shared by the larger system, including the family, school, military, health care, and community; 2) Experiences of wartime deployments and reintegration transitions - whether they are positive, costly or traumatic - may accumulate and reverberate throughout the family system. For children and families alike, these experiences become part of the developmental trajectory, and may be accelerated or buffered by a range of risk and resilience processes (Lester, 2012); 3) The experience and adjustment of at-home family members, particularly those caring for children, appear to be critical mediators of child adjustment and adaptation over time. The substantial task of modulating their own distress, children's reactions, as well as the returning service member's needs, can generate profound challenges for caregiving parents. 4) Across all of these experiences, a critical role for professionals is to assist service members, veterans and their families to organize, understand, make meaning, and communicate about their experiences. In particular, there is a critical need to communicate developmentally appropriate information about challenging experiences with children directly - despite an understandable inclination to avoid topics regarding danger, injury or loss. Taken as a whole, the larger systemic and social ecological frameworks shared by these articles suggest that empirically supported models which consider these perspectives are likely to be foundational to developing effective services for military connected families.

This issue is divided in to two clusters, with the first group of articles and commentary providing a detailed review of current research on military connected children, examining from a developmental perspective the distinct challenges that military children and families must navigate. Within this group, Paley, Lester and Mogil provide a foundational integration of family systems and social ecological theory to explore the processes by which deployment experiences impact military children and families, suggesting an empirically driven framework for family-centered approaches to prevention, intervention and treatment across developmental periods. Milburn and Lightfoot undertake a detailed examination of an understudied group, military connected adolescents, integrating emerging findings within a developmental framework, with particular attention to risk taking behaviors and key transition points, and underscoring important directions for future research. Examining the experience of children within the school ecology, Astor and colleagues (Tunac De Pedro, Gilreath, Esqueda, Benbenishty, 2013) provide a comprehensive review of data accumulated from literature on both civilian and military populations, and highlight reforms that can enhance the capacity of schools and surrounding systems (e.g., school districts, universities) to better meet the needs of military connected children. In a particularly insightful reflection on these contributions, Masten (2013) places the growing literature on military children and families within a larger context of convergent interdisciplinary research and theoretical 
approaches, citing a new "developmental systems theory" (Zelazo, 2013) as a compelling and relevant framework for our considerations for military connected families. Importantly, Masten also highlights the broader implications of research and clinical advancements with military families for other populations. Civilian families may face similar challenges (e.g., compromised attachment relationships, family conflict, loss of a parent,) albeit in different contexts (e.g., maltreatment, divorce, medical illness, community violence) and stand to benefit from the preventive and resilience-building approaches that are being implemented with military families.

The second group of articles examines emerging research and advance empirically based models for prevention, intervention and care for military connected families. While addressing different contexts and experiences (early childhood, family loss, parental injury), this set of articles provides an exciting expansion of approaches to prevention and interventions for military children and families. Lieberman and Van Horn's (2013) article provides a developmental and research framework (e.g. attachment considerations, parentchild intervention) for understanding the impact of parental separations on very young military children, and explores the experience of a parent's wartime service on these children, detailing with compelling and richly detailed examples the young child's perspective on fear, injury, and loss. Saltzman and colleagues (Saltzman, Pynoos, Lester, Beardslee, 2013) present an updated model of family resilience that highlights the central role of meaning making and positive belief structures for military connected families, and describe an intervention approach to family narrative construction that enhances the family's capacities to navigate stressful experiences in the context of deployment separations, reintegration transitions, and psychological and physical injuries. In a nuanced and thoughtful review of the impact of combat related parental injury or illness on children and families, Cozza, Holmes and Van Ost (2013) highlight the disruptive and destabilizing impact of these injuries on family life. The article notes that reintegration trajectories, including recovery from psychological or physical injury, are not linear for individuals or the family system, and that effective services and care systems should provide multiple points of entry for prevention and intervention. Kaplow and colleagues (Layne, Saltzman, Cozza and Pynoos, 2013) present a new multidimensional theory of grief to inform our understanding of how military children and families experience grief in the contexts of deployment, reintegration, and combat death, and call for practices that explicitly address the often unrecognized and untreated grief processes that these children and families face. In a thoughtful commentary to this group of articles, Beardslee (2013) emphasize the salience of family-centered prevention, intervention and care for military families facing the challenges of wartime deployments and their sequelae. In particular, his commentary provides a dynamic integration of theory and practice - as he elaborates upon the family's capacity to make meaning of their experiences as a "ongoing and iterative process," one which is central to enhancing individual and family resilience processes and supporting family relationships.

The contributions within Volume 1 underscore the potential relevance of family systems and social ecological models for emerging and future research about military and veteran children and families. Longitudinal research on children and families, some of it currently underway, will be needed to help clarify intermediate and longer-term effects of wartime military service on children and families, as well as causal pathways of risk and resilience processes across developmental periods, guiding our approaches to prevention, intervention and care. A more nuanced understanding of the experiences of military families across deployment and reintegration transitions, as well as a critical appraisal of current research findings will help inform the development of effective prevention, intervention and treatment approaches, as well as guide policy decisions that are central to addressing one of the major public health challenges of our generation (MacDermid-Wadsworth et al, 2013). 
Further, advances in the understanding of military connected children and families have much to teach us about all children and families facing challenges. Throughout history, the demands of war have led to many advances in the prevention and treatment of physical and psychological injuries. We anticipate that the fields of child development, family science and prevention and intervention research will advance as we learn more about the impact of war on children and families, as well as about the most effective strategies to address this impact and how to implement such strategies successfully. Taken together, these two volumes contribute to an integrated and detailed review of advancements in the field, provide new theoretical models for prevention and intervention, and set an agenda for research and policy priorities going forward.

\section{References}

Adamson, DM.; Burnam, MA.; Burns, RM.; Caldarone, LB.; Cox, RA.; D’Amico, E.; Diaz, C.; Eibner, C.; Fisher, G.; Helmus, TC.; Tanielian, T.; Karney, BR.; Kilmer, B.; Marshall, GN.; Martin, LT.; Meredith, LS.; Metscher, KN.; Osilla, KC.; Pacula, RL.; Ramchand, R.; Ringel, JS.; Schell, TL.; Sollinger, JM.; Jaycox, LH.; Vaiana, ME.; Williams, KM.; Yochelson, MR. Invisible Wounds of War: Psychological and Cognitive Injuries, Their Consequences, and Services to Assist Recovery. Santa Monica, CA: RAND Corporation; 2008. Available from: http://www.rand.org/ pubs/monographs/MG720. Also available in print form

Kemp, J.; Bossarte, R. Suicide Data Report. Department of Veterans Affairs Mental Health Services Suicide Prevention Program; 2012. Available from http://www.va.gov/opa/docs/Suicide-DataReport-2012-final.pdf

Lester PE. War and military children and families: translating prevention science into practice. Journal of the American Academy of Child and Adolescent Psychiatry. 2012; 51(1):3-5. [PubMed: 22176933]

MacDermid-Wadsworth S, Lester P, Marini C, Cozza S, Sornborger J, Strouse T, Beardslee W. Approaching Family-Focused Systems of Care for Military and Veteran Families. Military Behavioral Health. 2013; 1:31-40.

Maholmes V. Adjustment of children and youth in military families: Toward developmental understandings. Child Development Perspectives. 2012; 6:430-435.

Tanielian, T.; Ramchand, R.; Fisher, MP.; Sims, CS.; Harris, R.; Harrell, MC. Military Caregivers: Cornerstornes of Support for Our Nation's Wounded, Ill, and Injured Veterans. Santa Monica, CA: RAND Corporation; 2013. Available from: http://www.rand.org/pubs/research_reports/RR244. Also available in print form

Zelazo, PD. Developmental psychology: A new synthesis. In: Zelazo, PD., editor. The Oxford Handbook of Developmental Psychology. Vol. 1: Body and Mind. New York: Oxford University Press; 2013. p. 3-12. 